\title{
Targeted therapy with trastuzumab for epidermal growth factor receptor 2 (HER2)-positive advanced salivary duct carcinoma: A case report
}

\author{
TAKAHIKO GIBO ${ }^{1,2}$, NODOKA SEKIGUCHI ${ }^{2}$, DAISUKE GOMI ${ }^{2}$, TAKURO NOGUCHI $^{2}$, TOSHIROU FUKUSHIMA ${ }^{2}$, \\ TAKASHI KOBAYASHI ${ }^{2}$, TAKESUMI OZAWA ${ }^{2}$, SHIN-ICHI YAMADA ${ }^{1}$ and TOMONOBU KOIZUMI ${ }^{2}$ \\ ${ }^{1}$ Department of Dentistry and Oral Surgery; ${ }^{2}$ Department of Comprehensive Cancer Therapy, \\ Shinshu University School of Medicine, Matsumoto, Nagano 390-8621, Japan
}

Received July 16, 2018; Accepted April 22, 2019

DOI: $10.3892 / \mathrm{mco} .2019 .1875$

\begin{abstract}
Herein we report two cases of advanced and/or metastatic salivary duct carcinoma that relapsed after standard first-line chemotherapy. As overexpression of human epidermal growth factor receptor 2 (HER2) (3+) was observed by immunohistochemistry, the patients were treated with trastuzumab plus paclitaxel. One patient showed a complete response lasting over 2.5 years after the commencement of therapy; however, the other patient had no response to trastuzumab combined therapy. Dual fluorescence in situ hybridization was performed after the initiation of chemotherapy; the first case was positive for HER2 gene amplification, while the second case was negative. Our experiences suggest that therapy with HER2 blockers should be considered as options for treatment of HER2-positive salivary duct carcinoma. However, HER2 protein overexpression and gene amplification should be investigated further as therapeutic biomarkers.
\end{abstract}

\section{Introduction}

Salivary duct carcinoma (SDC), an aggressive and relatively rare tumor arising from the ductal epithelium of the salivary gland, accounts for approximately $10 \%$ of all salivary gland malignancies $(1,2)$. Nearly 100 cases of SDC are diagnosed each year in the world, and it arises almost exclusively in the major salivary glands. SDC is three times more common in men, and usually occurs in patients over 50 years of age (1-3). Generally, its prognosis is favorable if the primary lesion is completely resected and no metastases are present (2-5). However, local recurrence and distant metastasis represent the most common

Correspondence to: Professor Tomonobu Koizumi, Department of Comprehensive Cancer Therapy, Shinshu University School of Medicine, 3-1-1 Asahi, Matsumoto, Nagano 390-8621, Japan

E-mail: tomonobu@shinshu-u.ac.jp

Key words: dual fluorescence in situ hybridization, gene amplification, parotid gland tumor, paclitaxel forms of treatment failure (2-5). In a review of 104 cases of SDC, Barnes et al (3) reported that one third of patients experience local recurrence after curative treatment, with 59\% developing positive regional lymph nodes and $46 \%$ showing systemic metastases (lungs and bones). In addition, $65 \%$ of patients die of their disease usually within 4 years of initial diagnosis. In 141 cases of SDC in Japan, the 3-year overall survival and disease-free survival rates were 70.5 and $38.2 \%$, respectively (2). Treatment failure after initial surgery occurred in 78 patients, and $70 \%$ of these patients had distant metastases (2). Thus, the prognosis of progressive and metastatic diseases is poor, and effective systemic therapy is therefore important (2-5). Data regarding the efficacy of cytotoxic chemotherapeutic agents in cases of advanced and/or metastatic SDC are limited (2-5).

The histological findings of SDC are similar to those of ductal carcinoma of the breast $(2,3,6-8)$. Several studies indicated that the tumor cells sometimes overexpress human epidermal growth factor receptor 2 (HER2) in patients with SDC, at rates ranging from 20 to $77 \%$ (6-9). The humanized monoclonal antibody against HER2, trastuzumab, is expected to be effective in such cases. Indeed, several cases of advanced and/or metastatic SDC showed good responses to treatment with trastuzumab alone or along with chemotherapy (10-21). Therefore, trastuzumab is increasingly being used in the management of HER2/erB2-positive SDC. However, there remains insufficient evidence regarding the efficacy of treatment because of the rarity of the disease itself, particularly in Japanese patients.

Here, we describe two cases of HER2-overexpressing and advanced SDC treated with trastuzumab plus paclitaxel. A good response was obtained in one case, and the primary tumor mass and lymph node metastasis regressed with combined trastuzumab and paclitaxel therapy for over 2 years after initiation of treatment. Here, we report the clinical course of this case along with a review of the relevant literature focusing on HER-2 gene amplification.

\section{Case report}

Case 1. A 59-year-old man was referred to our hospital for further examination of a right cervical swelling and pain. Head and neck computed tomography (CT) (Fig. 1A) and magnetic 

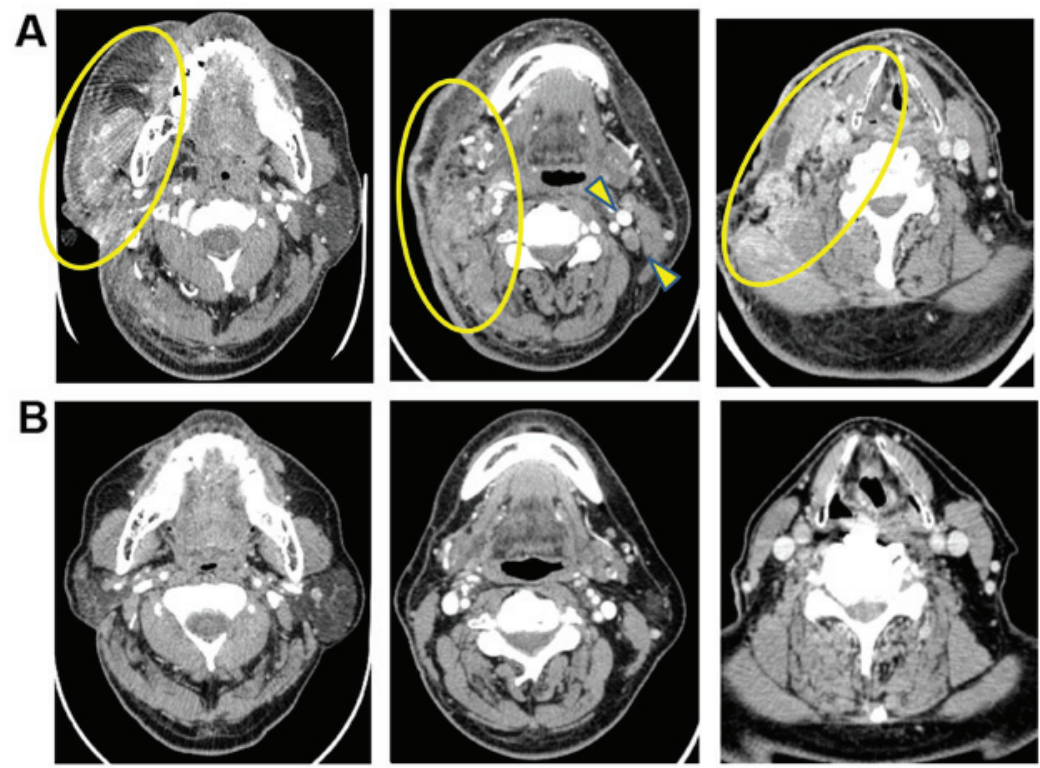

Figure 1. Computed tomography (CT) findings in case 1 before and after treatment with trastuzumab plus paclitaxel. (A) The tumor extended along the right cervical space and had metastasized into the left cervical lymph node before therapy (arrow). (B) The both metastatic tumors were reduced after 10 months of treatment with trastuzumab plus paclitaxel.

resonance imaging (MRI) showed a soft tissue mass shadow in the right cervical region. The soft tissue shadow spread into the trapezius muscle and broad neck muscles, masseter muscle, trapezius muscle, shoulder cap muscle, sternocleidomastoid muscle, carotid gap, pharyngopharyngeal space, and the subcutaneous soft tissue. Laboratory findings indicated increased carcinoembryonic antigen level $(59.6 \mathrm{mg} / \mathrm{ml})$. As percutaneous needle aspiration cytology revealed adenocarcinoma, open biopsy was performed and the histological diagnosis of SDC was confirmed (Fig. 2A). Chemotherapy with docetaxel $\left(60 \mathrm{mg} / \mathrm{m}^{2}\right.$, day 1$)$, cisplatin $\left(60 \mathrm{mg} / \mathrm{m}^{2}\right.$, day 1$)$, and 5-fluorouracil $\left(700 \mathrm{mg} / \mathrm{m}^{2}\right.$, days $\left.2-5\right)$ was performed with a 28-day cycle. However, four cycles of chemotherapy failed to reduce the soft tissue mass and symptoms. During chemotherapy, immunohistochemistry (IHC) of the biopsy specimen was performed and revealed that tumor cells were positive for HER2 (Fig. 3A) and negative for estrogen and progesterone receptors. The patient was then treated with trastuzumab plus paclitaxel. Trastuzumab was administered at a loading dose of $4 \mathrm{mg} / \mathrm{kg}$ followed by $2 \mathrm{mg} / \mathrm{kg}$ weekly in combination with weekly paclitaxel at $80 \mathrm{mg} / \mathrm{m}^{2}$. There were no adverse effects, including cardiotoxicity, neurotoxicity, and hematotoxicity. The right cervical soft tissue mass decreased in size and disappeared 10 months after initiation of chemotherapy (Fig. 1B). Although the therapy was discontinued due to paclitaxel-induced neurotoxicity, we used trastuzumab for over 2 years after complete response due to concerns regarding early relapse. This patient remained well over 2 years after cessation of trastuzumab.

Case 2. A 68-year-old man was referred to our hospital for further chemotherapy as treatment for relapsed SDC. He underwent total right parotidectomy with cervical lymphadenectomy and facial nerve reconstruction using the femoral nerve. The pathological diagnosis was SDC. However, he developed pulmonary metastasis 6 months after the operation and received several chemotherapeutic regimens, including platinum compounds plus docetaxel or 5-fluorouracil, and cetuximab plus paclitaxel. However, the disease was progressive and chest $\mathrm{CT}$ showed multiple metastatic nodules in both lungs (Fig. 4A). IHC analysis of the resected primary tumor indicated that the tumor cells were positive for HER2 (Fig. 3B). Therefore, the patient was treated with trastuzumab plus paclitaxel at the same dose and according to the same schedule as in case 1 . However, the therapy (six cycles of trastuzumab plus paclitaxel) failed to improve radiographic findings in the lungs (Fig. 4B), and the patient was followed up by best supportive care. The patient died due to respiratory failure 6 months later.

The treatment in both cases was approved by the institutional review board of Shinshu University Hospital (approval number: B0290) and was conducted in accordance with the principles of the Declaration of Helsinki. Dual fluorescence in situ hybridization was performed after initiation of trastuzumab combined with chemotherapy in both cases. Case 1 was positive for HER2 gene amplification (Fig. 3C), while the findings were negative in case 2 (Fig. 3D).

\section{Discussion}

We reported two cases of advanced and metastatic HER2-overexpressing SDC (3+) treated with trastuzumab and paclitaxel chemotherapy. One patient, who was positive for HER2 gene amplification, showed a complete response lasting for over 2.5 years after commencement of therapy. However, the other patient, who was negative for HER 2 gene amplification, showed no response to trastuzumab combined therapy.

Recently, Ghazali et al (13) reported a patient with HER2-positive metastatic salivary adenocarcinoma who showed complete response to trastuzumab, and summarized 15 published papers, including a prospective study and a case report, presenting details of 56 cases treated with trastuzumab monotherapy or combined chemotherapy. Although the dose 
A

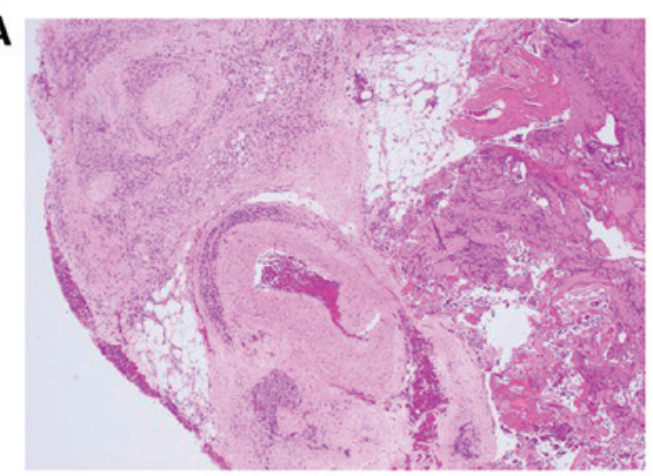

B

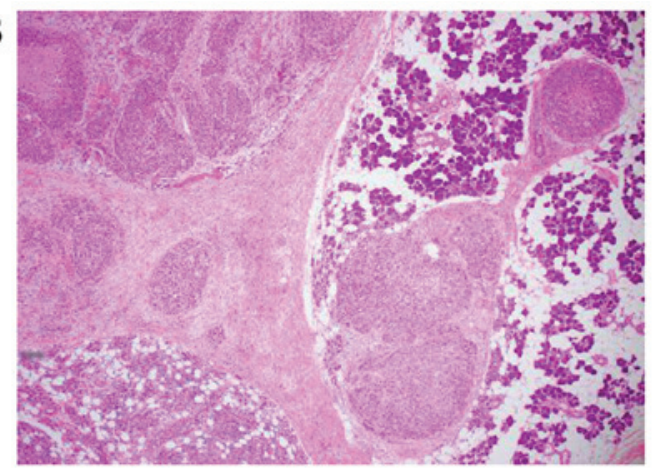

Figure 2. Pathological findings on hematoxylin and eosin (H\&E) staining in both cases. (A) Case 1: Within the salivary gland tissue, heterozygous cells with eosinophilic cytoplasm and prominent nucleoli proliferated with comedo-like central necrosis. (B) Case 2: Heterotypic cells with nuclear enlargement invasively proliferated with atypical ductal epithelial cells in a cribriform growth pattern. H\&E, x40 magnification.
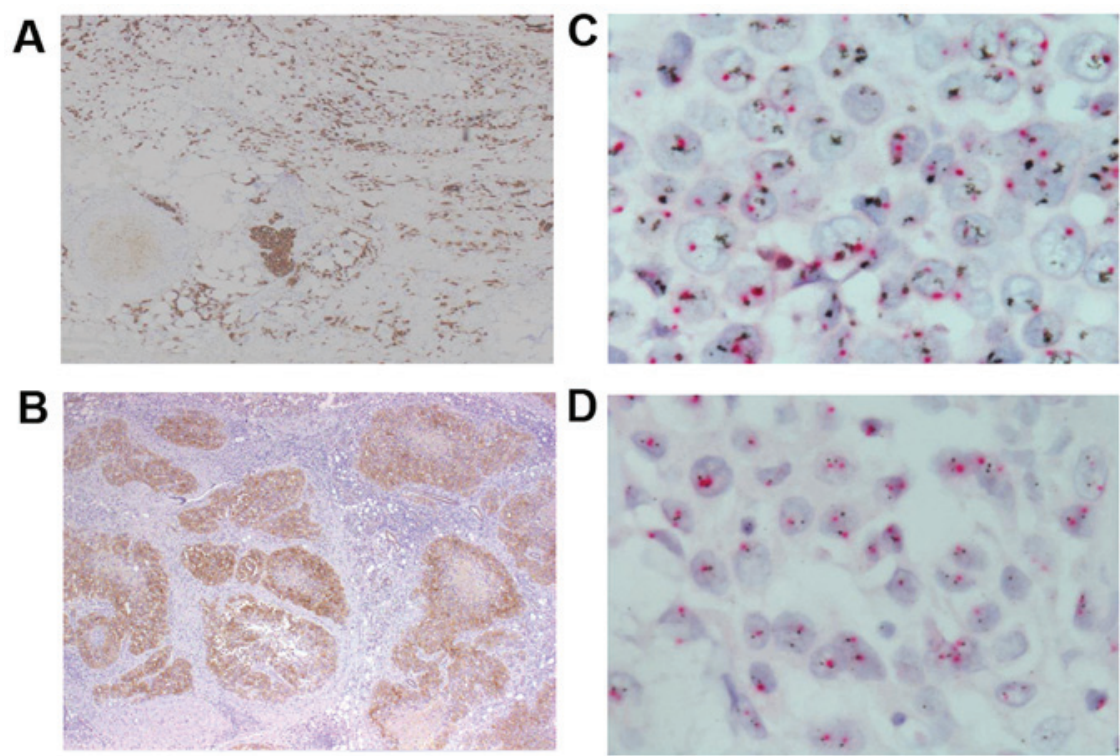

Figure 3. Immunohistochemical (IHC) analysis and determination of HER2 gene amplification by dual-color in situ hybridization (DISH). HER2 overexpression was positive in tumor cells from both cases (A, case 1; B, case 2), but only case 1 was positive for HER2 gene amplification (C) while case 2 was negative (D) HER2 IHC x40 magnification; HER2 DISH, x100 magnification.
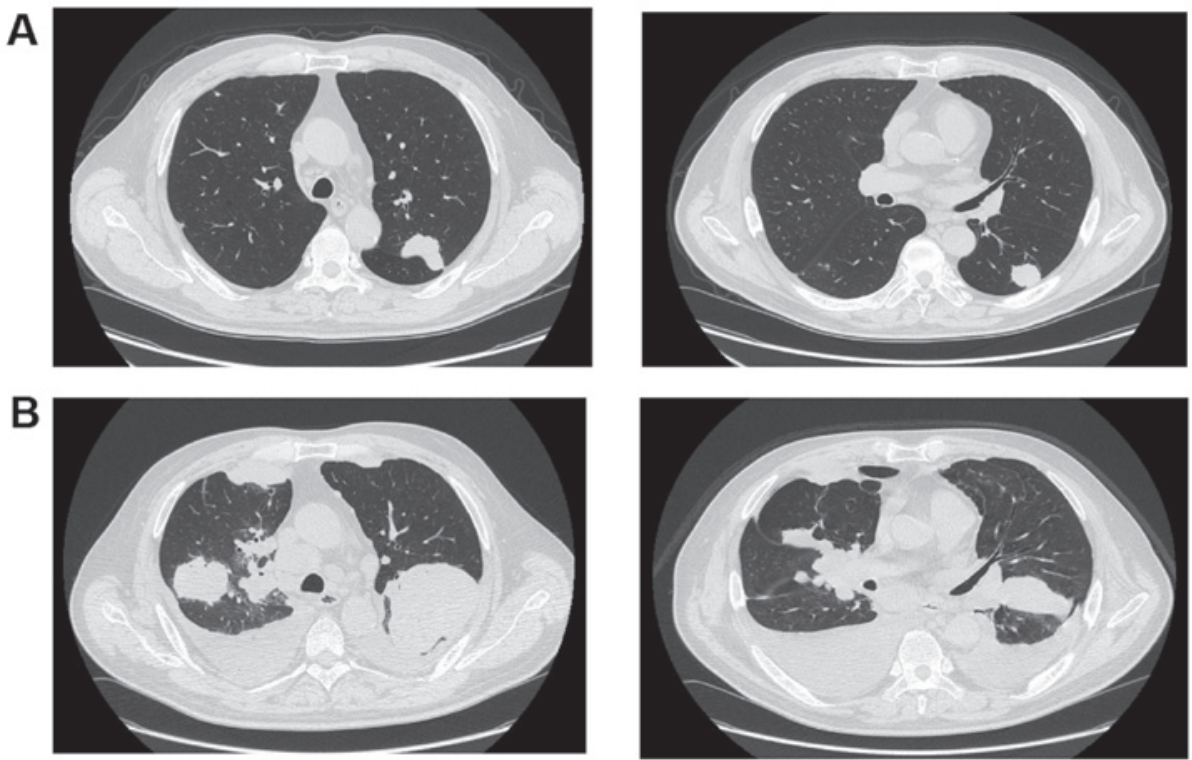

Figure 4. Chest computed tomography findings before (A) and after (B) treatment with trastuzumab plus paclitaxel in case 2. 
and schedule of trastuzumab and combined chemotherapy agents were different between the reports, 22 patients achieved good response. In addition, there were disparities regarding the criteria for HER 2 overexpression in these reports. A phase II trial of trastuzumab enrolled 14 patients with salivary grand carcinoma overexpressing HER2 over 2+ as determined by IHC, and showed only one case of partial response lasting longer than 2 years (16). HER2 was a potential therapeutic target in salivary grand carcinoma. However, HER2 overexpression evaluated by IHC was not always associated with significant efficacy of tumor response to trastuzumab.

In recent case reports showing the usefulness of trastuzumab in SDC, overexpression of HER2 was evaluated by both IHC and gene amplification (9-11,14-22). Limaye et al (17) reported five cases of SDC positive for both HER2 on IHC and for HER2 gene amplification, treated with trastuzumab combined with chemotherapy. All patients showed good response and the median duration of response was 18 months (range, 8-52 months). Thus, the response to trastuzumab chemotherapy in patients may be dependent on HER2 overexpression and gene amplification. Our case 1 showed good response, and was also positive for both HER2 overexpression and gene amplification. Based on these findings and our experience, we emphasize that both HER2 protein overexpression and gene amplification should be examined as therapeutic biomarkers in SDC.

There have been several studies regarding the coexistence of HER2 IHC and gene amplification in SDC. Thirteen of 14 Japanese cases of HER2 IHC (3+) were positive on FISH (6). Cornolti et al (7) reported eight cases of FISH positivity among 10 with grade $3+$ IHC. Dagrada et al (8) reported a coexistence rate of 73\% (8/11 cases) on IHC and FISH assessment. In addition, Skalova et al (11) reported three cases of FISH positivity among seven with IHC positivity over grade $3(3+)$ in salivary gland carcinoma. These concordance rates were lower than that in breast adenocarcinomas $(>90 \%)$ with high $(3+)$ HER2 expression (22). Further case studies presenting details of HER2 examination and treatment for advanced salivary malignancies are warranted.

In addition, the therapeutic effects of trastuzumab are related to the immunological backgrounds (23). White blood cell and lymphocyte counts were 7,660 and 1,800 in case 1 and 6,140 and 1,600 in case 2 before trastuzumab therapy, respectively. Although we did not examine the specific immunological parameters in both cases, we should pay attention to the immunological examination in patients with HER-2 positive SDC.

In summary, our experiences indicated that HER2 should be examined in patients with advanced and/or metastatic SDC, and that findings of both HER2 overexpression and gene amplification define a group of patients with SDC who would benefit from targeted therapy with trastuzumab.

\section{Acknowledgements}

Not applicable.

\section{Funding}

No funding was received.

\section{Availability of data and materials}

The datasets used and/or analyzed during the present study are available from the corresponding author on reasonable request.

\section{Authors' contributions}

TG, NS and TKoi wrote the manuscript and all authors TG, NS, DG, TN, TF, TKob, TO, SY and TKoi treated the patients. All authors read and approved the final manuscript.

\section{Ethics approval and consent to participate}

The Ethics Committees of Shinshu University Hospital approved the treatment of two cases (approval number: B0290).

\section{Patient consent for publication}

Not applicable.

\section{Competing interests}

The authors declare that they have no competing interests.

\section{References}

1. McHugh JB, Visscher DW and Barnes EL: Update on selected salivary gland neoplasms. Arch Pathol Lab Med 133: 1763-1774, 2009.

2. Otsuka K, Imanishi Y, Tada Y, Kawakita D, Kano S, Tsukahara K, Shimizu A, Ozawa H, Okami K, Sakai A, et al: Clinical outcomes and prognostic factors for salivary duct carcinoma: A multi-institutional analysis of 141 patients. Ann Surg Oncol 23: 2038-2045, 2016.

3. Barnes L, Rao U, Krause J, Contis L, Schwartz A and Scalamogna P: Salivary duct carcinoma. Part I. A clinicopathologic evaluation and DNA image analysis of 13 cases with review of the literature. Oral Surg Oral Med Oral Pathol 78: 64-73, 1994

4. Johnston ML, Huang SH, Waldron JN, Atenafu EG, Chan K, Cummings BJ, Gilbert RW, Goldstein D, Gullane PJ, Irish JC, et al: Salivary duct carcinoma: Treatment, outcomes, and patterns of failure. Head Neck 38: E820-E826, 2016.

5. Lagha A, Chraiet N, Ayadi M, Krimi S, Allani B, Rifi H, Raies H and Mezlini A: Systemic therapy in the management of metastatic or advanced salivary gland cancers. Oral Oncol 48: 948-957, 2012.

6. Masubuchi T, Tada Y, Maruya S, Osamura Y, Kamata SE, Miura K, Fushimi C, Takahashi H, Kawakita D, Kishimoto S and Nagao T: Clinicopathological significance of androgen receptor, HER2, Ki-67 and EGFR expressions in salivary duct carcinoma. Int J Clin Oncol 20: 35-44, 2015.

7. Cornolti G, Ungari M, Morassi ML, Facchetti F, Rossi E, Lombardi D and Nicolai P: Amplification and overexpression of HER2/neu gene and HER2/neu protein in salivary duct carcinoma of the parotid gland. Arch Otolaryngol Head Neck Surg 133: 1031-1036, 2007.

8. Dagrada GP, Negri T, Tamborini E, Pierotti MA and Pilotti S: Expression of HER-2/neu gene and protein in salivary duct carcinomas of parotid gland as revealed by fluorescence in-situ hybridization and immunohistochemistry. Histopathology 44: 301-302, 2004.

9. Alotaibi AM, Alqarni MA, Alnobi A and Tarakji B: Human epidermal growth factor receptor 2 (HER $2 /$ neu) in salivary gland carcinomas: A review of literature. J Clin Diagn Res 9: ZE04-ZE08, 2015.

10. Nabili V, Tan JW, Bhuta S, Sercarz JA and Head CS: Salivary duct carcinoma: A clinical and histologic review with implications for trastuzumab therapy. Head Neck 29: 907-912, 2007.

11. Skálová A, Stárek, Kucerová V, Szépe P and Plank L: Salivary duct carcinoma-A highly aggressive salivary gland tumor with HER-2/neu oncoprotein overexpression. Pathol Res Pract 197: 621-626, 2001. 
12. De Block K, Vander Poorten V, Dormaar T, Nuyts S, Hauben E, Floris G, Deroose CM, Schöffski P and Clement PM: Metastatic HER-2-positive salivary gland carcinoma treated with trastuzumab and a taxane: A series of six patients. Acta Clin Belg 71: 383-388, 2016.

13. Ghazali N, Parker L, Settle K and Lubek JE: Sustained response of HER2-positive metastatic salivary adenocarcinoma, not otherwise specified, treated with trastuzumab. Oral Surg Oral Med Oral Pathol Oral Radiol 122: 292-299, 2016.

14. Kadowaki S, Yatabe Y, Hirakawa H, Komori A, Kondoh C, Hasegawa Y and Muro K: Complete response to trastuzumab-based chemotherapy in a patient with human epidermal growth factor receptor-2-positive metastatic salivary duct carcinoma ex pleomorphic adenoma. Case Rep Oncol 6: 450-455, 2013.

15. Iqbal MS, Shaikh G, Chatterjee S, Cocks H and Kovarik J: Maintenance therapy with trastuzumab in her2 positive metastatic parotid ductal adenocarcinoma. Case Rep Oncol Med 2014: 16251634,2014

16. Haddad R, Colevas AD, Krane JF, Cooper D, Glisson B, Amrein PC, Weeks L, Costello R and Posner M: Herceptin in patients with advanced or metastatic salivary gland carcinomas. A phase II study. Oral Oncol 39: 724-727, 2003.

17. Limaye SA, Posner MR, Krane JF, Fonfria M, Lorch JH, Dillon DA, Shreenivas AV, Tishler RB and Haddad RI: Trastuzumab for the treatment of salivary duct carcinoma. Oncol 18: 294-300, 2013.

18. Thorpe LM, Schrock AB, Erlich RL, Miller VA, Knost J, Le-Lindqwister N, Jujjavarapu S, Ali SM and Liu JJ: Significant and durable clinical benefit from trastuzumab in 2 patients with HER2-amplified salivary gland cancer and a review of the literature. Head Neck 39: E40-E44, 2017.
19. Corrêa TS, Matos GDR, Segura M and Dos Anjos CH: Second-line treatment of HER2-positive salivary gland tumor: Ado-Trastuzumab emtansine (T-DM1) after progression on trastuzumab. Case Rep Oncol 11: 252-257, 2018.

20. van Boxtel W, Boon E, Weijs WLJ, van den Hoogen FJA, Flucke UE and van Herpen CML: Combination of docetaxel, trastuzumab and pertuzumab or treatment with trastuzumab-emtansine for metastatic salivary duct carcinoma. Oral Oncol 72: 198-200, 2017.

21. Iguchi F, Taniguchi Z, Kusano J, Takahashi Y and Murai N: A case of metastatic salivary duct carcinoma successfully treated with trastuzumab-based targeted therapy. Nihon Jibiinkoka Gakkai Kaiho 117: 1108-1114, 2014 (Japanese).

22. Giltnane JM, Molinaro A, Cheng H, Robinson A, Turbin D, Gelmon K, Huntsman D and Rimm DL: Comparison of quantitative immunofluorescence with conventional methods for HER2/neu testing with respect to response to trastuzumab therapy in metastatic breast cancer. Arch Pathol Lab Med 132: 1635-1647, 2008

23. Ethier JL, Desautels D, Templeton A, Shah PS and Amir E: Prognostic role of neutrophil-to-lymphocyte ratio in breast cancer: A systematic review and meta-analysis. Breast Cancer Res 19: 2, 2017 International (CC BY-NC-ND 4.0) License. 